\title{
Antioxidant and antimitotic activities of sulfated polysaccharide from marine brown algae Padina tetrastromatica
}

\author{
Geena Mariya Jose, R. Anitha, G. Muraleedhara Kurup* \\ Department of Biochemistry, University of Kerala, Karyavattom, Thiruvananthapuram, Kerala, India
}

Received: 16.11 .2015
Accepted: 26.12 .2015
Accepted: 29.12.2015
Published: 29.12.2015
*Address for
correspondence:
G. Muraleedhara Kurup,
Department of
Biochemistry, University
of Kerala, Karyavattom,
Thiruvananthapuram, Kerala,
India. E-mail: gmkbio@
gmail.com

gmail.com

\begin{abstract}
Antioxidants play a central role in the prevention of carcinogenesis. The most natural compounds exhibit their protective effects by eliciting antioxidant potential. A sulfated polysaccharide (SPS) was isolated from the brown algae Padina tetrastromatica, and then purified and evaluated for its composition and in vitro antioxidant and antimitotic activities. Both ethanolic sulfated polysaccharide (ESPS) and ethanolic sulfated polysaccharide-column purified (ESPS-CP) exhibited considerable amount of carbohydrates (11.2\% and $17.6 \%)$, sulfate (11.4\% and $7.4 \%)$, fucose $(5.5 \%$ and $15.7 \%)$, uronic acid $(4.7 \%$ and $11.8 \%)$, xylose $(0.5 \%$ and $0.03 \%)$, and SPS $(2.4 \%$ and $12.7 \%)$ content. The Fourier transform infrared analysis and phytochemical screening also confirmed the presence of SPS. In the in vitro antioxidant activity determination using 1-1-diphenyl 2-picryl hydrazyl radical scavenging activity, hydroxyl radical scavenging activity, superoxide anion scavenging activity, hydrogen peroxide scavenging activity, total antioxidant activity and reducing power, ESPS showed more activity than ESPS-CP. In the case of nitric oxide radical scavenging, ESPS-CP was found to be a more effective. At a concentration of $2 \mathrm{mg} / \mathrm{ml}$, both samples were potent antioxidants with significant $\mathrm{IC}_{50}$ values. The antimitotic studies such as mitotic index in onion root tips and sprouting assay in green gram seeds also proved that both the extracts are able to prevent mitosis. The extrapolation of these results can find opportunities in therapeutic regiments of cancer.
\end{abstract}

KEY WORDS: Antioxidant activity, mitotic index, Padina tetrastromatica, sprouting assay, sulfated polysaccharide

\section{INTRODUCTION}

The exploitation of natural products for developing novel drugs has been highly appreciated. Although these biochemical face certain obstacles in bioavailability and isolation, they can overcome most of the difficulties evoked by synthetic drugs and therapeutics (da Rocha et al., 2001). For instance, around $60 \%$ of the anticancer drugs are of natural derivatives and several are in clinical and pre-clinical trials (Patwardhan and Vaidya, 2010). The occurrences of the vast diversity of secondary metabolites, such as alkaloids and terpinoids, make phytomedicine a better choice for the management of diseases such as cancer, diabetes and heart attack. Vincristine, etoposide, paclitaxel, and irinotecan are some of plant-derived anticancer drugs that have been benefited millions of sufferers throughout the globe (Alam et al., 2014).

Along with terrestrial plants, the marine vegetation has also gained impact in pharmaceuticals and therapeutics
(Schwartsmann et al., 2001). Seaweeds from the richest renewable source of many bioactive compounds which makes them a vital candidate in drug development (Thomas and Kim, 2013). The prosperous and diverse marine vegetation consists of many bioactive compounds such as polyunsaturated fatty acids, proteins, polysaccharides, and pigments that form the basis of novel medicinal products (Senthilkumar et al., 2013). Among the seaweed-born macromolecules, the sulfated polysaccharides (SPS) from marine macroalgae are reported to possess antioxidant, anti-inflammatory, antiallergic, anticancer, antiviral, and anticoagulant activities despite their structural and nutritional roles (Ngo and Kim, 2013). Heterofucans from brown seaweed Dictyopteris delicatula was reported to have anticoagulant, antioxidant, and antitumor activities (Magalhaes et al., 2011). The dependence of sulfate content on the bioactivity of SPS has been well-established ( $\mathrm{Li}$ et al., 2008). 
Oxidative stress, due to the overproduction of reactive oxygen species (ROS) and reactive nitrogen species, can cause damage to nucleic acids, proteins, or lipids which eventually can lead to cardiovascular and neurodegenerative diseases, Alzheimer's and cancer (Dayem et al., 2010). The most destructive one among these is cancer. These highly reactive species cause impairment in replication, transcriptional and translational errors and genomic instability, all of which finally result in cancer (Ogasawara and Zhang, 2009). Antioxidants are competent in scavenging these reactive species to prevent cancer development (Bennett et al., 2012). Numerous genera of marine algae, including Colpomenia, Gracilaria, Halymenia, Hydroclathrus, Laurencia, Padina, Polysiphonia, and Turbinaria, have been reported to have antioxidant property (Kelman et al., 2012). SPS from brown, green and red algae were found to have antioxidant property and can form candidates for cancer therapy (Ngo and Kim, 2013; Costa et al., 2011; Qi et al., 2005).

The brown algae Padina tetrastromatica, belongs to the order dictyotales of phaeophyta phylum, is found abundant in Indian coastal areas (Mohan et al., 2014). P. tetrastromatica was proved to be a rich source of the most essential nutrients including vitamin B1, B2, B6, and minerals such as copper, manganese, zinc, lead, etc. (Sethi, 2012). However, the anticancer potential of SPS from P. tetrastromatica is yet to be identified. The present study aimed on the in vitro determination of antioxidant potential of crude and partially purified fractions of SPS from P. tetrastromatica.

\section{MATERIALS AND METHODS}

\section{Chemicals}

All chemicals used in this study were of analytical grade obtained from Sisco Research Laboratories, Mumbai, Maharashtra, India.

\section{Collection of Seaweed}

Samples of $P$. tetrastromatica were collected from the Vizhinjam coast of Kerala, (Lat. $8^{\circ} 22^{\prime} \mathrm{N}$; Long. $76^{\circ} 59^{\prime} \mathrm{E}$ on the west coast of India) during the month of JanuaryFebruary. The Professor and Botanist Dr. M.V.N Panikkar, Department of Botany, S.N. College, Kollam, Kerala, identified the algal material and a voucher herbarium specimen (No. KUBH 5804) was kept in the herbarium of Department of Botany, University of Kerala, India.

\section{Extraction, Isolation, and Purification of SPS}

The collected $P$. tetrastromatica were cleaned in tap water and then with distilled water. The samples were dried, powdered in a blender and stored in dark within airtight containers. The SPS from the algae were extracted using cold acidic extraction method (Suresh et al., 2013). Briefly, $100 \mathrm{~g}$ of the powdered algae was soaked in an acetonemethanol (7:3) mixture for 2 days under continuous shaking for removing pigments and other lipophilic constituents. After evaporating the solvents, $0.1 \mathrm{~N} \mathrm{HCl}$ added to the dried biomass left out and stirred for $24 \mathrm{~h}$. This step repeated twice. The filtrates kept overnight at $4{ }^{\circ} \mathrm{C}$ and precipitated by adding an equal amount of absolute ethanol. Ethanol was evaporated, and the precipitate was lyophilized in the freeze dryer (Labconco 2.5 Plus, Germany).

The SPS were purified using diethylaminoethyl (DEAE) cellulose anion exchange chromatography (Athukorala et al., 2006). The crude ethanolic extract was applied to a DEAE-cellulose column $(17 \mathrm{~cm} \times 2.5 \mathrm{~cm})$ equilibrated with $50 \mathrm{mM}$ sodium acetate $(\mathrm{pH}$ 5.0). The SPS were eluted using sodium acetate buffer containing $\mathrm{NaCl}$ with graded concentrations $(0.1 \mathrm{M}, 0.5 \mathrm{M}, 0.75 \mathrm{M}, 1 \mathrm{M}, 1.5 \mathrm{M}$ and $2 \mathrm{M}$, respectively). $5 \mathrm{ml}$ fractions were collected, and the polysaccharides content was determined by the phenol-sulfuric acid method. The fractions that showed highest values were pooled and dialyzed against distilled water for 2 days at $4{ }^{\circ} \mathrm{C}$ and freeze-dried for further evaluations.

\section{Phytochemical Screening}

\section{Test for reducing sugar}

About $0.5 \mathrm{ml}$ of the extract was mixed with $2 \mathrm{ml}$ of an equal amount of Fehling's solution A and Fehling's solution $\mathrm{B}$ and the mixture was kept in a boiling water bath for $5 \mathrm{~min}$. Appearance of brick red precipitate indicates the presence of reducing sugar (Wadood, 2013).

\section{Test for flavonoids}

To $1 \mathrm{ml}$ of the extract few drops of $10 \% \mathrm{FeCl}_{3}$ was added and observed for the appearance of green or blue which indicates the presence of flavonoids (Ali Hassan and Abu Bakar, 2013).

\section{Test for amino acids}

$1 \mathrm{ml}$ of the extract was treated with few drops of ninhydrin reagent, heated in water bath for $1 \mathrm{~min}$; purple color indicates the presence of amino acids (Ali Hassan and Abu Bakar, 2013).

\section{Test for tannins}

$0.5 \mathrm{ml}$ of $1 \%$ lead acetate was added to $0.5 \mathrm{ml}$ of extract, and the presence of tannins is indicated by the appearance of a yellow precipitate (Ali Hassan and Abu Bakar, 2013). 


\section{Test for alkaloids}

To $1 \mathrm{ml}$ of test sample, few drops of con $\mathrm{HCl}$ and $1 \mathrm{ml}$ Mayer's reagent were added and the turbidity or yellow precipitate indicates the presence of alkaloids (Ali Hassan and Abu Bakar, 2013).

\section{Test for glycosides}

Test sample was evaporated and dissolved in $1 \mathrm{ml}$ glacial acetic acid. 1 drop of $10 \% \mathrm{FeCl}_{3}$ was added. Then $1 \mathrm{ml}$ con $\mathrm{H}_{2} \mathrm{SO}_{4}$ was added through the sides. The occurrence of the brown ring at the interface indicates glycosides (Ali Hassan and Abu Bakar, 2013).

\section{Test for steroids}

The test sample was evaporated and dissolved in $2 \mathrm{ml}$ chloroform, and $2 \mathrm{ml}$ con $\mathrm{H}_{2} \mathrm{SO}_{4}$ was added along the sides of the test tube. Formation of a red ring indicates the presence of steroids (Ali Hassan and Abu Bakar, 2013).

\section{Test for saponins}

$2 \mathrm{ml}$ of distilled water and a pinch of sodium bicarbonate was added to the sample and shacked vigorously. Honey comb like appearance indicates the presence of saponins (Singh et al., 2012).

\section{Test for terpenoids}

$2 \mathrm{ml}$ chloroform was added to the test sample, and con $\mathrm{H}_{2} \mathrm{SO}_{4}$ was added along the sides of the test tubes. The appearance of a red ring indicates the presence of terpenoids (Wadood, 2013).

\section{Determination of Chemical Composition}

\section{Estimation of total carbohydrates}

Total carbohydrate content was estimated by the phenolsulfuric acid method as described by Thinh et al. (2013). About 5\% phenol and concentrated sulfuric acid were added to the test sample $(10 \mathrm{mg} / \mathrm{ml})$, incubated for $20 \mathrm{~min}$ and optical density (OD) was read at $490 \mathrm{~nm}$. Dextrose was used as a standard.

\section{Estimation of sulfate content}

The sulfate content was determined by barium chloridegelatin method using potassium sulfate as standard (Rocha de Souza et al., 2007). The reaction mixture was prepared by adding $2 \mathrm{~g}$ barium chloride to a solution of $0.6 \mathrm{~g}$ gelatin in $200 \mathrm{ml}$ water which was kept overnight at $4^{\circ} \mathrm{C}$. To the test solution $(10 \mathrm{mg} / \mathrm{ml}) 4 \% \mathrm{TCA}$ and $1 \mathrm{ml}$ chloride gelatin solution was added, and OD was read at $360 \mathrm{~nm}$ after 15 min incubation.

\section{Estimation of uronic acid}

Uronic acid content of the extract was estimated by carbazole method using glucuronic acid as standard
(Kumar et al., 2014). The test sample $(10 \mathrm{mg} / \mathrm{ml})$ was heated in a boiling water bath for 10 min with $0.025 \mathrm{M}$ borax. Then $0.1 \%$ carbazole (in methanol) was added, and boiling was continued for $15 \mathrm{~min}$. The OD was read at $540 \mathrm{~nm}$.

\section{Estimation of fucose}

Fucose content was determined using cysteine hydrochloride (Sawke and Sawke, 2010). Concentrated sulfuric acid was added to the test sample $(10 \mathrm{mg} / \mathrm{ml})$ for $3 \mathrm{~min} .3 \%$ cysteine hydrochloride was added, and the difference in the OD at $396 \mathrm{~nm}$ and $427 \mathrm{~nm}$ was calculated.

\section{Estimation of SPSM}

Total SPS were determined by metachromatic assay using heparin as standard (Liao et al., 2009). 0.005\% toluidine blue solution and $0.2 \% \mathrm{NaCl}$ were added to the test sample $(10 \mathrm{mg} / \mathrm{ml})$ and was mixed well for $30 \mathrm{~s}$. Then $\mathrm{n}$-hexane was added to the above mixture, and the $5 \mathrm{ml}$ aqueous layer was separated. Equal volume of absolute ethanol was added and the OD was read at $631 \mathrm{~nm}$.

\section{Estimation of xylose}

The monosaccharide xylose was estimated using orcinol method (Blackmore andWilliams, 1974). $0.1 \mathrm{ml}$ of sample $(10 \mathrm{mg} / \mathrm{ml})$ was heated in a boiling water bath for $30 \mathrm{~min}$. OD was read at $670 \mathrm{~nm}$.

\section{Functional Group Analysis of Isolated Polysaccharide by infrared (IR) Spectroscopy}

The functional groups present in the crude and purified samples were determined by Fourier transform infrared (FT-IR) spectral analysis. The freeze-dried samples were scanned using a $\mathrm{KBr}$ window using IR spectrophotometer (Nicolet 5700 FT-IR Spectrometer, Thermo Electron Corp., USA).

\section{In Vitro Antioxidant Activity of Crude and Purified Extracts}

\section{DPPH (1-1-diphenyl 2-picryl hydrazyl) radical scavenging activity}

DPPH free radical scavenging activity was determined by the method described by Garcia et al. (Manochai et al., 2010). Different concentrations of samples were prepared in ethanol. The reaction mixture for test sample consists of $0.5 \mathrm{ml}$ of sample, $3 \mathrm{ml}$ of absolute ethanol and $0.3 \mathrm{ml}$ of DPPH radical solution ( $0.5 \mathrm{mM}$ in ethanol). A mixture of $3.3 \mathrm{ml}$ ethanol and $0.5 \mathrm{ml}$ sample served as blank and $3.5 \mathrm{ml}$ ethanol and $0.3 \mathrm{ml}$ DPPH radical solution used as a control. Ascorbic acid at different concentrations $(5-25 \mu \mathrm{g} / \mathrm{ml})$ was used as the standard. All the tubes were read at $517 \mathrm{~nm}$ after 100 min of reaction using a 
UV-VIS spectrophotometer. The DPPH radical scavenging potential of the test sample was determined by using the formula:

$$
\% \text { of scavenging }=\frac{\mathrm{OD}_{\text {control }}-\mathrm{OD}_{\text {test }}}{\mathrm{OD}_{\text {control }}} \times 100
$$

\section{Hydroxyl radical scavenging activity}

The hydroxyl radical scavenging activity was determined using Fenton reaction (Corpuz et al., 2013). The reaction mixture consists of $1 \mathrm{mM}$ ferric chloride, 30 $\mathrm{mM}$ deoxyribose, $1 \mathrm{mM}$ ascorbic acid, $1 \mathrm{mM}$ EDTA and $20 \mathrm{mM} \mathrm{H}_{2} \mathrm{O}_{2}$ in $0.2 \mathrm{M}$ phosphate buffer. $0.2 \mathrm{ml}$ of gradient concentrations of test samples was incubated with $1 \mathrm{ml}$ of the reaction mixture at room temperature for $1 \mathrm{~h} .0 .2 \mathrm{ml}$ phosphate buffer instead of the test sample was used as control and $1.2 \mathrm{ml}$ phosphate buffer served as blank. After incubation $1 \mathrm{ml}$ thiobarbituric acid (TBA) trichloroacetic acid (TCA) reagent (1\% TBA and 15\% TCA in $0.25 \mathrm{~N}$ $\mathrm{HCl}$ ) was added to all the tubes and incubated in boiling water bath for $20 \mathrm{~min}$. The reduction in color due to the scavenging of hydroxyl radical was read at $532 \mathrm{~nm}$. Ascorbic acid at different concentrations $(50-300 \mu \mathrm{g} / \mathrm{ml})$ was used as the standard. The hydroxyl radical scavenging ability was determined using the formula:

$$
\% \text { of scavenging }=\frac{\mathrm{OD}_{\text {control }}-\mathrm{OD}_{\text {test }}}{\mathrm{OD}_{\text {control }}} \times 100
$$

\section{Superoxide anion scavenging activity}

The superoxide anion scavenging activity was determined by using nitro blue tetrazolium (NBT) reduction method (Senthilkumar et al., 2013). The reaction mixture contained $0.02 \mathrm{ml}$ of different concentrations of extracts, $0.05 \mathrm{ml}$ of riboflavin solution $(0.12 \mathrm{mM}), 0.2 \mathrm{ml}$ of EDTA solution $(0.1 \mathrm{M})$ and $0.1 \mathrm{ml} \mathrm{NBT}$ solution $(1.5 \mathrm{mM})$ which is finally diluted up to $2.64 \mathrm{ml}$ using phosphate buffer $(0.067 \mathrm{M})$. Reaction mixture devoid of sample served as control. The difference in OD at $560 \mathrm{~nm}$ was taken after illuminating under fluorescent light for 5 and $30 \mathrm{~min}$. Quercetin (20-100 $\mu \mathrm{g} / \mathrm{ml}$ ) served as standard. The scavenging percentage was determined using the formula:

$$
\% \text { of scavenging }=\frac{\mathrm{OD}_{\text {control }}-\mathrm{OD}_{\text {test }}}{\mathrm{OD}_{\text {control }}} \times 100
$$

\section{Nitric oxide radical scavenging activity}

Nitric oxide scavenging activity was determined by using Griess reaction (Shukla et al., 2012). $0.5 \mathrm{ml}$ of graded concentrations of the test sample in methanol was incubated with $3 \mathrm{ml}$ sodium nitroprusside $(5 \mathrm{mM})$ in phosphate buffer at $25^{\circ} \mathrm{C}$ for $30 \mathrm{~min} .0 .5 \mathrm{ml}$ of phosphate-buffered saline (PBS) instead of test sample was used as control. After incubation $1.5 \mathrm{ml}$ Griess reagent (1\% sulfanilamide, 2\% $\mathrm{H}_{3} \mathrm{PO}_{4}$ and $0.1 \%$ napthyl ethylene diaminedihydrochloride) was added to all the tubes and the absorbance was read at $546 \mathrm{~nm}$ using PBS as blank. Ascorbic acid (100-500 $\mu \mathrm{g} /$ $\mathrm{ml}$ ) was used as the standard. The percentage of scavenging was measured using the formula:

$$
\% \text { of scavenging }=\frac{\mathrm{OD}_{\text {control }}-\mathrm{OD}_{\text {test }}}{\mathrm{OD}_{\text {control }}} \times 100
$$

\section{Hydrogen peroxide scavenging activity}

$0.5 \mathrm{ml}$ of graded concentrations of the test sample in methanol was added to $0.6 \mathrm{ml}$ of $40 \mathrm{mM} \mathrm{H}_{2} \mathrm{O}_{2}$ solution in phosphate buffer and incubated for $10 \mathrm{~min}$ at room temperature. $0.5 \mathrm{ml}$ of phosphate buffer instead of test served as control and phosphate buffer without $\mathrm{H}_{2} \mathrm{O}_{2}$ as blank. Reduction in OD was read at $230 \mathrm{~nm}$. Ascorbic acid in different concentrations $(20-100 \mu \mathrm{g} / \mathrm{ml})$ was used as the standard (Ramani et al., 2012). Percentage of $\mathrm{H}_{2} \mathrm{O}_{2}$ scavenging was determined by the formula;

$$
\% \text { of scavenging }=\frac{\mathrm{OD}_{\text {control }}-\mathrm{OD}_{\text {test }}}{\mathrm{OD}_{\text {control }}} \times 100
$$

\section{Total antioxidant activity (TAA)}

The TAA was determined by using the procedure described by Do QD et al. (2012). $0.3 \mathrm{ml}$ of different concentrations of the test sample was mixed with $3 \mathrm{ml}$ of the reagent $(1 \mathrm{ml}$ each of $0.6 \mathrm{M}$ sulfuric acid, $28 \mathrm{mM}$ sodium phosphate, and $4 \mathrm{mM}$ ammonium molybdate). $0.3 \mathrm{ml}$ of distilled water instead of test sample was used as blank. All the tubes were incubated at $90^{\circ} \mathrm{C}$ for $90 \mathrm{~min}$ and the absorbance was read at $695 \mathrm{~nm}$. The Gallic acid in different concentrations (20-100 $\mu \mathrm{g} / \mathrm{ml})$ was used as the standard. TAA is expressed as equivalent of ascorbic acid.

\section{Reducing Power}

Different concentrations of test samples $(1 \mathrm{ml})$ were incubated with $2.5 \mathrm{ml} \mathrm{1 \%}$ potassium ferricyanide and $2.5 \mathrm{ml}$ phosphate buffer $(0.2 \mathrm{M}, \mathrm{pH} 6.6)$ at $50^{\circ} \mathrm{C}$ for $20 \mathrm{~min} .1 \mathrm{ml}$ of distilled water instead of the test was used as blank. After incubation $2.5 \mathrm{ml}$ 10\% TCA was added and then centrifuged at $3000 \mathrm{rpm}$ for $10 \mathrm{~min} .2 .5 \mathrm{ml}$ of the upper layer was then mixed with $2.5 \mathrm{ml}$ distilled water, and $0.5 \mathrm{ml}$ of $0.1 \%$ ferric chloride was added to all the tubes. Absorbance was read at $700 \mathrm{~nm}$ (Zhao et al., 2014). The Gallic acid in different concentrations $(20-100 \mu \mathrm{g} / \mathrm{ml})$ served as blank, and the reducing power is expressed as ascorbic acid equivalent. 


\section{Determination of Antimitotic Activity}

\section{Inhibition of water imbibition and sprouting in green gram seeds}

Green gram seeds of equal weight were germinated in $500 \mu \mathrm{l}$ of graded concentrations of crude extract in a 24-well microtiter plate. After $24 \mathrm{~h}$, the seeds were dried on a dry tissue paper and weighed. Seeds germinated in distilled water served as the control and that in drug doxorubicin as the standard (Kumar and Singhal, 2009). For the morphological study, the length of the radical was observed. Percentage inhibition of water imbibition was determined by the formula:

$$
\% \text { of inhibition }=\frac{(\mathrm{Ww}-\mathrm{Dw})_{\mathrm{control}}-(\mathrm{Ww}-\mathrm{Dw})_{\mathrm{test}}}{(\mathrm{Ww}-\mathrm{Dw})_{\mathrm{control}}}
$$

Ww - Wet weight of green gram seeds Dw - Dry weight of green gram seeds

\section{Inhibition of mitosis in onion root tips}

Inhibition of mitosis by crude extract was determined using Allium cepa (onion) roots (Saboo et al., 2012). Onion bulbs were allowed to sprout in water at room temperature for $48 \mathrm{~h}$. Bulbs that developed uniform roots were then dipped in different concentration of the test sample for $3 \mathrm{~h}$. Distilled water was used as the control and the drug doxorubicin as the standard. After $3 \mathrm{~h}$ root tips were transferred to a fixing solution (acetic acid:Ethanol in the ratio of $1: 3 \mathrm{~V} / \mathrm{V}$ ) for 10-12 h. The roots were then stained using acetocarmine stain and observed under microscope (Leica DM IL LED, Germany). Mitotic index and inhibition of mitosis were calculated as follows:

$$
\text { Mitotic index }(\mathrm{MI})=\frac{\text { Number of dividing cells }}{\text { Number of total cells }} \times 100
$$$$
\% \text { of mitotic inhibition }=\frac{\mathrm{MI}_{\text {control }}-\mathrm{MI}_{\text {test }}}{\mathrm{MI}_{\text {control }}}
$$

\section{Statistical Analysis}

All evaluations include six samples from each group. Oneway analysis of variance was calculated by using online software for statistic calculations. The $P<0.05$ were considered to be significant (Finosh and Jayabalan, 2015; Finosh et al., 2015).

\section{RESULTS}

The ethanolic sulfated polysaccharide (ESPS) obtained by ethanol precipitation was designated as ESPS and its yield was found to be $17 \%(w / w)$. Further, purification was done using DEAE cellulose column chromatography. Column purification of ESPS showed the highest carbohydrate yield in fractions 7-11 of $0.5 \mathrm{M} \mathrm{NaCl}$. These fractions were pooled and lyophilized to obtain ethanolic sulfated polysaccharide-column purified (ESPS-CP) and its yield was found to be $9 \%(\mathrm{w} / \mathrm{w})$. The elution profile of DEAE cellulose column chromatography is shown in Figure 1. The chemical composition of ESPS and ESPS-CP are given in Table 1 . The percentage of total carbohydrate was greater in purified sample than that of ethanolic one. However, the sulfate and xylose content were less in ESPS and ESPS-CP. At the same time, percentage of fucose, uronic acid, and SPS are a higher in purified sample.

FT-IR spectral analysis was used to determine the major functional groups present in ESPS and ESPS-CP (Figure 2). The broad peak around 3200-3500 indicates the presence

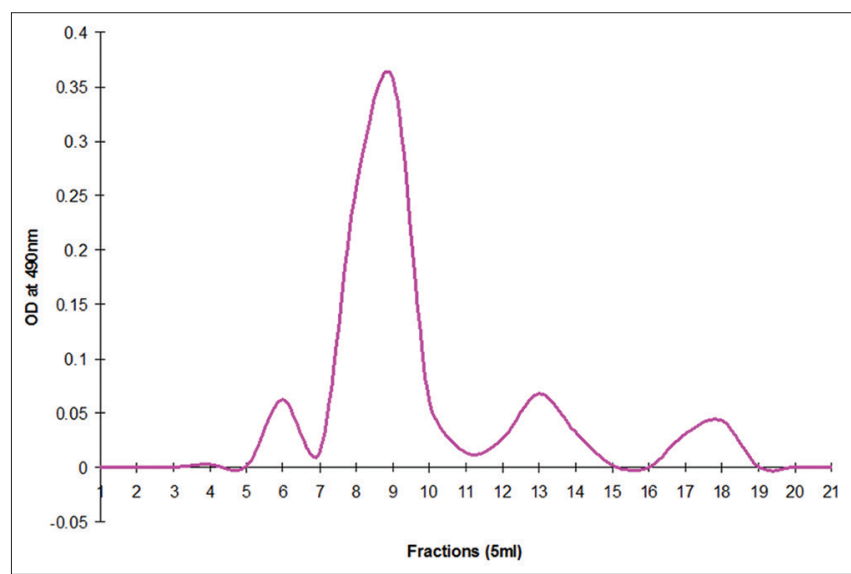

Figure 1: lon-exchange chromatography (DEAE-cellulose) of sulfated polysaccharide isolated from brown marine algae $P$. tetrastromatica. Fractions 7 to 11 , eluted with $0.5 \mathrm{M} \mathrm{NaCl}$, showed highest amount of carbohydrate and were pooled to obtain Ethanolic Sulfated polysaccharide-Column Purified (ESPS-CP).

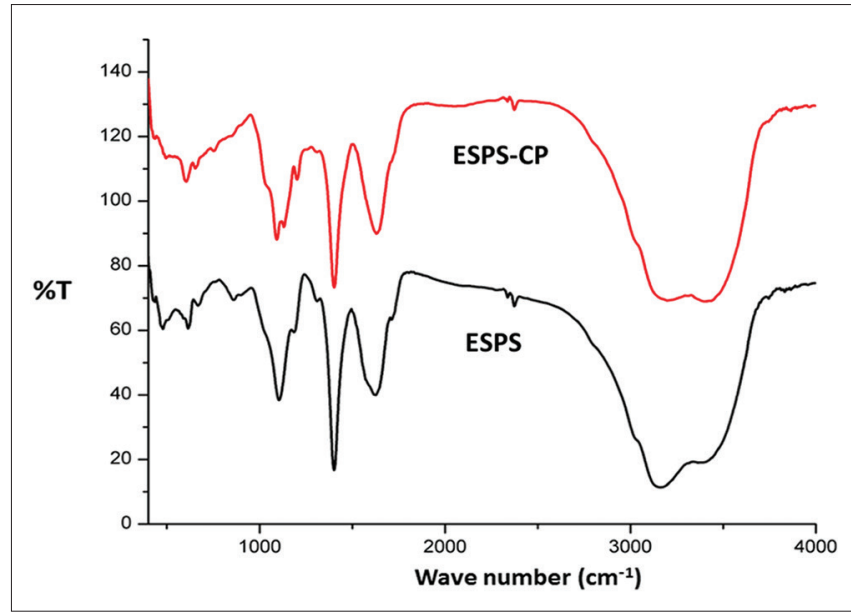

Figure 2: FT-IR spectral analysis to determine the functional groups present in the extracts. 
of ample amounts of -OH functional groups on both the extracts. This may also be due to the presence of primary $-\mathrm{NH}_{2}$ groups. The peak appearing $\sim 1620 / \mathrm{cm}$ is an indication of double bonds, which might be contributed by the secondary metabolites. The sharp peak at $1402 / \mathrm{cm}$ was an indication of bending of $\mathrm{C}-\mathrm{H}$ bonds present in SPS and in secondary metabolites. The peak at $1100 /$ cmindicates the -C-O- stretch of glycosidic bonds of the SPS and the $\mathrm{S}=\mathrm{O}$ stretch. The intensities of most of the peaks were found to be reduced in ESPS on comparing with ESPS-CP, which may be due to the removal of phytochemicals, by purification. The feeble peak around $700 / \mathrm{cm}$ also indicates the presence of thioester groups. From these, it can be concluded that the active component of both the extracts can be SPS. The results were compared with the standard SPS for confirmation as reported elsewhere (Badrinathan et al., 2012; Saboural et al., 2014).

Table 2 represents the phytochemical composition of both ESPS and ESPS-CP. The result shows that crude extract

Table 1: Chemical composition ESPS and ESPS-CP

\begin{tabular}{lcc}
\hline Composition & ESPS & ESPS-CP \\
\hline Carbohydrates (\%) & 11.2 & 17.6 \\
Sulfate (\%) & 11.4 & 7.4 \\
Fucose (\%) & 5.5 & 15.7 \\
Uronic acid (\%) & 4.7 & 11.8 \\
Sulfated polysaccharide (\%) & 2.4 & 12.7 \\
Xylose (\%) & 0.5 & 0.03 \\
\hline
\end{tabular}

ESPS: Ethanolic sulfated polysaccharide, ESPS-CP: Ethanolic sulfated polysaccharide-column purified contains other metabolites such as flavonoids steroids and terpenoids. The column-purified sample contains only reducing sugar and glycosides, the normal constituents of polysaccharides, which in turn accounts for the purity of the isolated polysaccharide.

The antioxidant potential of both ESPS and ESPS-CP were determined using various methods and compared with standard antioxidants. The crude samples (ESPS) showed more activity than purified sample (ESPS-CP) except in the case of nitric oxide radical scavenging. The DPPH radical scavenging activity of ethanolic (ESPS) and purified (ESPS-CP) samples are depicted in Figure 3. Both ESPS and ESPS-CP exhibited a dosedependent increase in the DPPH scavenging activity. The $\mathrm{IC}_{50}$ values of ESPS, ESPS-CP, and ascorbic acid were found to be $1.6,2.5$, and $0.2 \mathrm{mg} / \mathrm{ml}$ respectively. The hydroxyl radical scavenging potential of ESPS and ESPS-CP is given in Figure 3. All samples exhibited a dose-dependent increase in the percentage of free radical scavenging. The $\mathrm{IC}_{50}$ values of ESPS and ESPS-CP were found to be 1.9 , and $2.1 \mathrm{mg} / \mathrm{ml}$ respectively. At the same time, ascorbic acid exhibited 50\% scavenging ability at $0.27 \mathrm{mg} / \mathrm{ml}$. At a concentration of $1.5 \mathrm{mg} / \mathrm{ml}$, ESPS exhibited 50\%, and ESPS-CP showed 44\% inhibition of superoxide radicals. In the case of standard quercetin, $50 \%$ inhibition was observed at $0.9 \mathrm{mg} / \mathrm{ml}$ (Figure 3). The nitric oxide scavenging efficiency of ESPS and ESPS-CP showed a reverse trend than that of the other

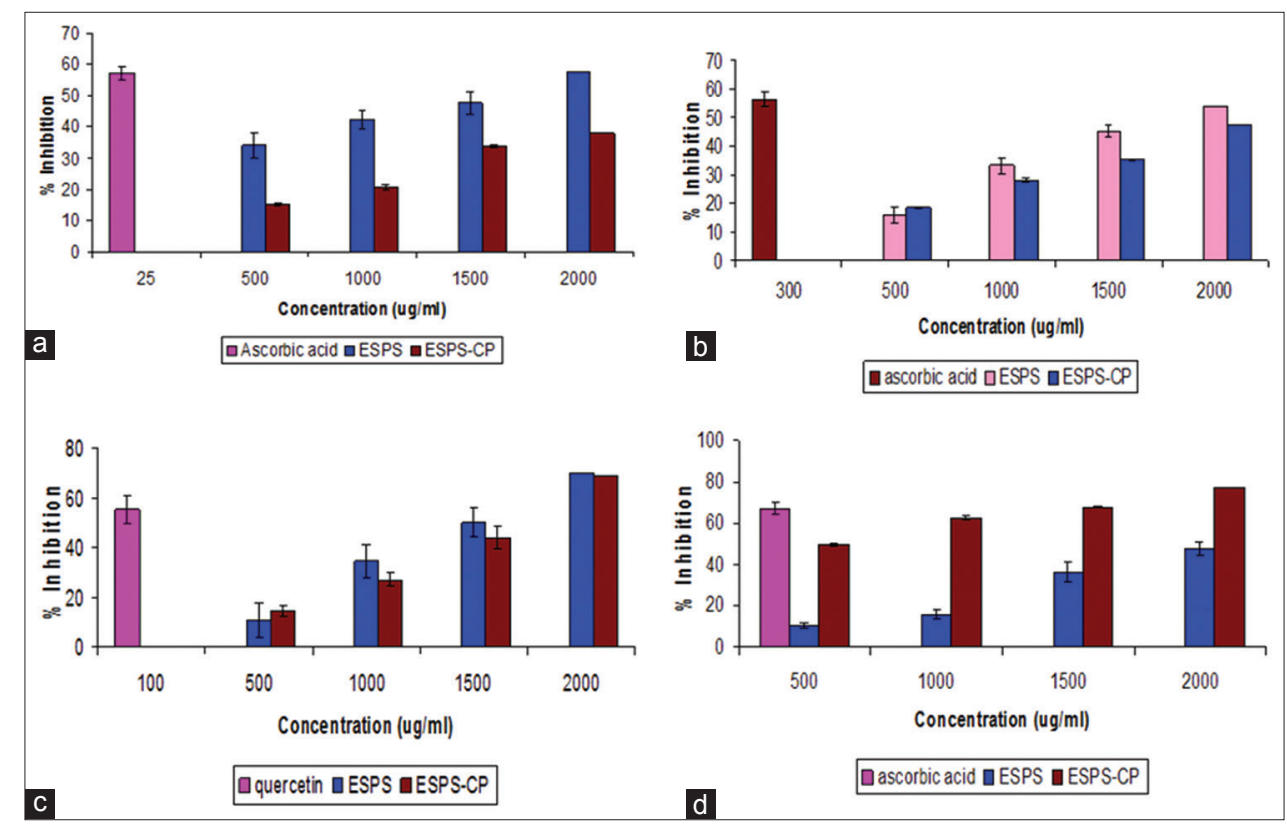

Figure 3: a) DPPH radical scavenging activity of ethanolic (ESPS) and purified (ESPS-CP) samples using ascorbic acid as reference standard. b) Hydroxyl radical scavenging potential of ESPS and ESPS-CP. Ascorbic acid was used as the positive control. c) Super oxide radicals scavenging activity of ethanolic (ESPS) and purified (ESPS-CP) samples using quercetin as the reference standard. d) The nitric oxide scavenging efficiency of ESPS and ESPS-CP. Ascorbic acid was used as the positive control. 
antioxidant parameters (Figure 3). Here, the purified sample ESPS-CP showed $50 \%$ inhibition at $0.5 \mathrm{mg} / \mathrm{ml}$ concentration, whereas the crude sample showed less activity $(50 \%$ at $2.3 \mathrm{mg} / \mathrm{ml})$. Ascorbic acid showed $50 \%$ scavenging at $0.3 \mathrm{mg} / \mathrm{ml}$. The hydrogen peroxide scavenging potential of ESPS and ESPS-CP proved ESPS to be a potent inhibitor of hydrogen peroxide. The $\mathrm{IC}_{50}$ values of ESPS, ESPS-CP, and ascorbic acid were found to be $0.9,14.1$, and $0.04 \mathrm{mg} / \mathrm{ml}$, respectively. A dosedependent increase in the percentage of $\mathrm{H}_{2} \mathrm{O}_{2}$ scavenging was observed (Figure 4). The TAA of ethanolic (ESPS) and purified (ESPS-CP) samples are shown in Figure 4.
$1 \mathrm{mg} / \mathrm{ml}$ of ESPS showed $30.8 \mu \mathrm{g} / \mathrm{ml}$ equivalence of ascorbic acid where as for the same concentration of ESPS-CP it was $15 \mu \mathrm{g} / \mathrm{ml}$ equivalence of ascorbic acid. For the positive control, gallic acid $100 \mu \mathrm{g} / \mathrm{ml}$ was equivalent to $83 \mu \mathrm{g} / \mathrm{ml}$ equivalence of ascorbic acid. The reducing power of both the samples is shown in Figure 4. Here both ESPS and ESPS-CP showed extremely low activity when compared to gallic acid standard. $1 \mathrm{mg} /$ $\mathrm{ml}$ of ESPS showed $18 \mu \mathrm{g} / \mathrm{ml}$ equivalence of ascorbic acid where as for the same concentration of ESPS-CP it was $4 \mu \mathrm{g} / \mathrm{ml}$ equivalence of ascorbic acid. The purified sample ESPS-CP showed very less reducing power when

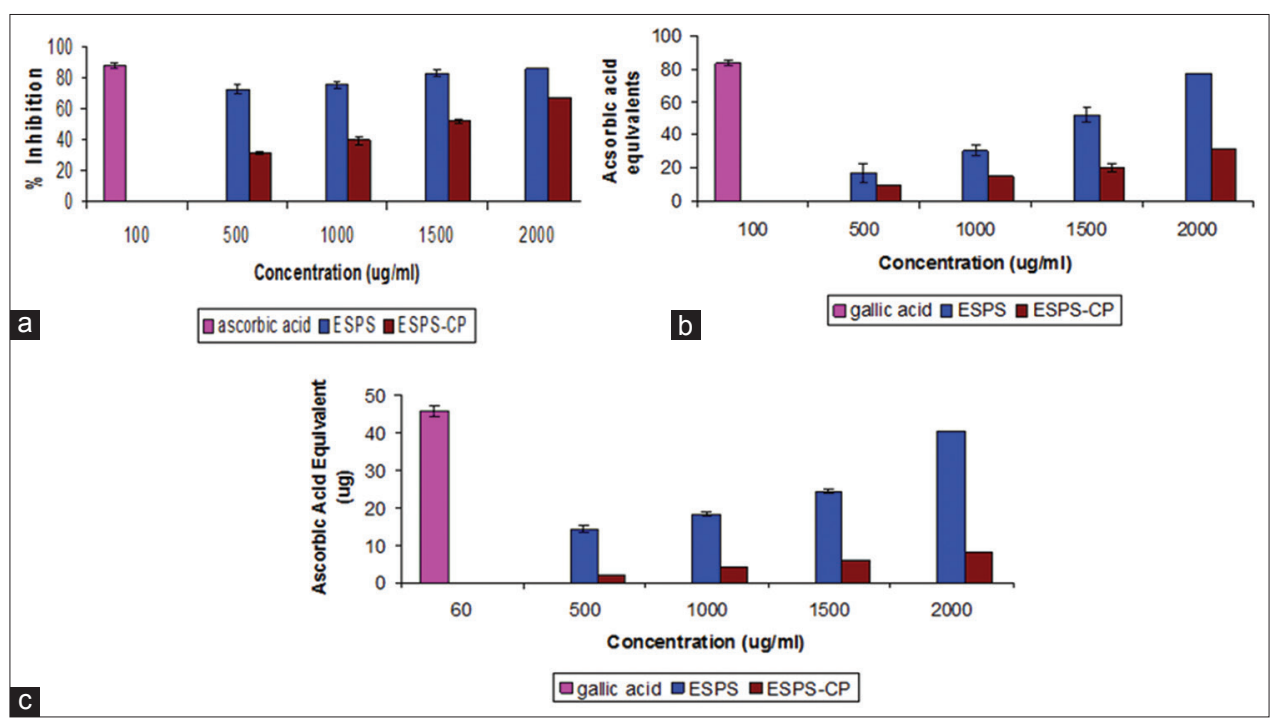

Figure 4: a) The hydrogen peroxide scavenging potential of ESPS and ESPS-CP using ascorbic acid as the standard. b) The total antioxidant activity of ethanolic (ESPS) and purified (ESPS-CP) using gallic acid as the positive control. c) The reducing power of ESPS and ESPS-CP. Gallic acid was used as the positive control.

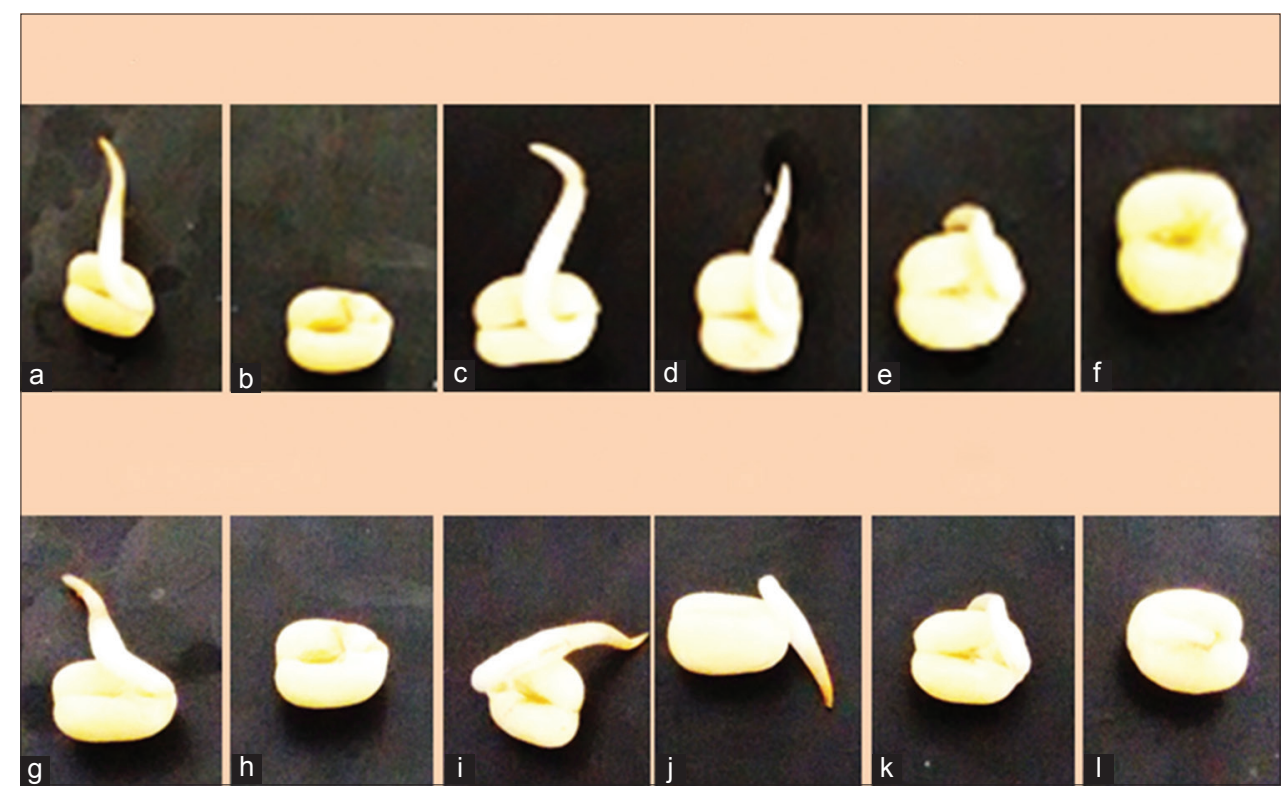

Figure 5: Anti mitotic activity of ESPS and EASPS-CP by inhibiting sprouting in green gram seeds. a\&G) Distilled water, b\&H) Doxorubicin, c) ESPS $0.5 \mathrm{mg} / \mathrm{ml}$, d) ESPS $1 \mathrm{mg} / \mathrm{ml}$, e) ESPS $1.5 \mathrm{mg} / \mathrm{ml}$, f) ESPS $2 \mathrm{mg} / \mathrm{ml}$, l) ESPS CP $0.5 \mathrm{mg} / \mathrm{ml}$, j) ESPS CP $1 \mathrm{mg} / \mathrm{ml}, \mathrm{k}$ ) ESPS CP $1.5 \mathrm{mg} / \mathrm{ml}$, l) ESPS CP $2 \mathrm{mg} / \mathrm{ml}$. 


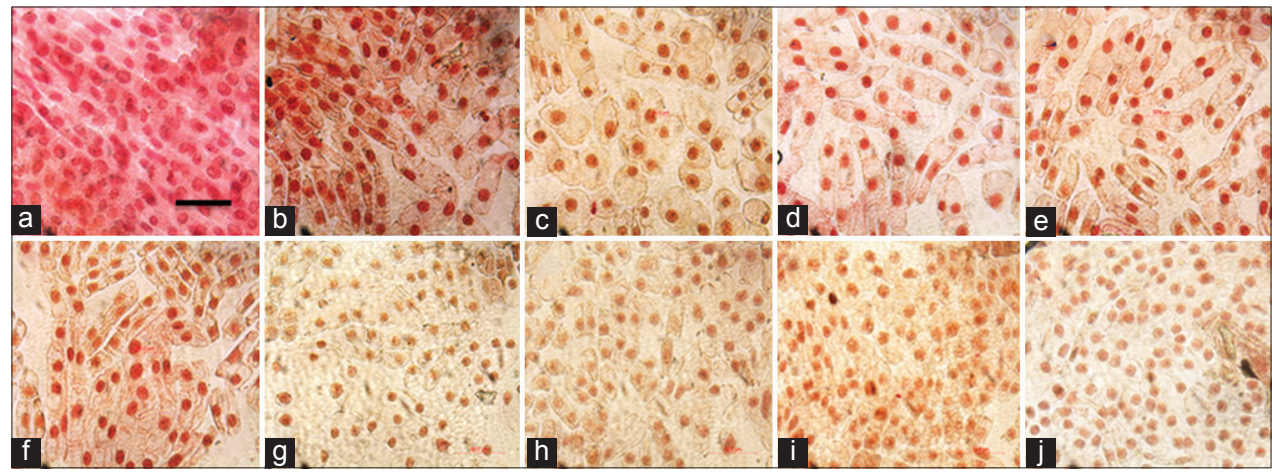

Figure 6: Anti mitotic activity of ESPS and ESPS CP by inhibiting cell division in onion root tip. a) Distilled water, b) Doxorubicin, c) ESPS $0.5 \mathrm{mg} / \mathrm{ml}$, d) ESPS $1 \mathrm{mg} / \mathrm{ml}$, e) ESPS $1.5 \mathrm{mg} / \mathrm{ml}$, f) ESPS $2 \mathrm{mg} / \mathrm{ml}$, g) ESPS CP $0.5 \mathrm{mg} / \mathrm{ml}$, h) ESPS CP $1 \mathrm{mg} / \mathrm{ml}$, i) ESPS CP $1.5 \mathrm{mg} / \mathrm{ml}$, j) ESPS CP $2 \mathrm{mg} / \mathrm{ml}$,

compared to crude sample. For the positive control, gallic acid $100 \mu \mathrm{g} / \mathrm{ml}$ was equivalent to $85 \mu \mathrm{g} / \mathrm{ml}$ equivalence of ascorbic acid.

Both ESPS and ESPS CP showed inhibition of water imbibition (Table 3). At a concentration of $1.5 \mathrm{mg} / \mathrm{ml}$ both extracts showed a comparable effect to that of $0.1 \mathrm{mg} / \mathrm{ml}$ doxorubicin. Here, also the crude sample is better than purified as in the case of antioxidant activity. The morphological examination revealed that extracts also showed a dose-dependent inhibition of seed germination (Figure 5).

The mitotic index of the onion root tips treated with both ESPS and ESPS CP is given in Table 4. There is a decrease in the mitotic index with increase in the concentration of the drug. At a concentration of $2 \mathrm{mg} / \mathrm{ml}$ both extracts showed a comparable effect to that of $0.1 \mathrm{mg} / \mathrm{ml}$ doxorubicin. Here, also the crude sample showed more activity when compared to the purified one (Figure 6).

\section{DISCUSSION}

The present study is aimed at the extraction, purification, and characterization of SPS with antioxidant potential from brown algae, P. tetrastromatica. Here, we used direct ethanolic precipitation to obtain the ethanolic sample. Various reports are already available regarding the isolation of SPS from brown algae. In the hot acidic extraction of fucose-containing sulfated polysaccharides from brown algae Sargassum sp. using $\mathrm{HCl}$, the yield was reported to be $7.1 \%$ (Ale et al., 2011). Relatively higher yield was obtained for our samples. However, the purified sample yields lower SPS content than the crude one. This is because the DEAE column is specific for the isolation of negatively charged compounds and thus, the purified fraction contained only the negatively charged SPS devoid of other contaminants like phytochemicals (Thinh et al.,
Table 2: Phytochemical analysis of ESPS and ESPS-CP

\begin{tabular}{lcc}
\hline Parameters & ESPS & ESPS-CP \\
\hline Reducing sugar & ++ & ++ \\
Flavanoids & ++ & - \\
Amino acids & - & - \\
Tannins & + & - \\
Alkaloids & - & - \\
Glycosides & ++ & ++ \\
Steroids & + & \\
Saponins & - & - \\
Terpenoids & + & - \\
\hline
\end{tabular}

ESPS: Ethanolic sulfated polysaccharide, ESPS-CP: Ethanolic sulfated polysaccharide-column purified

Table 3: Inhibition of water imbibition by ESPS and ESPS-CP in Green gram seeds

\begin{tabular}{lcccc}
\hline Concentration $(\mathrm{mg} / \mathrm{ml})$ & \multicolumn{4}{c}{ \% inhibition of water imbibition } \\
\cline { 2 - 5 } & 0.5 & 1 & 1.5 & 2 \\
\hline ESPS & 14.3 & 25.45 & 36.8 & 42.45 \\
ESPS-CP & 23.41 & 32.25 & 38.3 & 41.1 \\
Doxorubicin $(0.1 \mathrm{mg} / \mathrm{ml})$ & 34.5 & & & \\
\hline
\end{tabular}

ESPS: Ethanolic sulfated polysaccharide, ESPS-CP: Ethanolic sulfated polysaccharide-column purified

Table 4: MI showing inhibition of mitosis in onion root tips by ESPS and ESPS-CP

\begin{tabular}{lcccc}
\hline Concentration $(\mathrm{mg} / \mathrm{ml})$ & \multicolumn{4}{c}{ MI in \% } \\
\cline { 2 - 5 } & 0.5 & 1 & 1.5 & 2 \\
\hline ESPS & 96.7 & 92.2 & 90.7 & 86.5 \\
ESPS-CP & 93.5 & 97.5 & 91.7 & 86.9 \\
Doxorubicin $(0.1 \mathrm{mg} / \mathrm{ml})$ & 87.7 & & & \\
Distilled water & 100 & & & \\
\hline
\end{tabular}

ESPS: Ethanolic sulfated polysaccharide, ESPS-CP: Ethanolic sulfated polysaccharide-column purified, MI: Mitotic index

2013). In short, the column fractionation is a feasible method for the isolation of SPS from brown algae as it shows specificity toward negatively charged SPS.

The SPS from brown algae are mainly hetero fucans composed of fucose, sulfate, xylose, glucose, galactose and uronic acid (Thinh et al., 2013). Several reports are available which deals with the chemical composition of 
SPS from brown algae (Costa et al., 2011; Magalhaes et al., 2011). Some reports substantiate the presence of high percentage of total carbohydrates (above 50\%) in brown seaweeds (Yang et al., 2011; Melo et al., 2013). Still, some others reported lower carbohydrate contents in brown algae like Sargassum tenerrimum (8.2\%) (Vijayabaskar and Vaseela, 2012). The total carbohydrate content of ESPS was found to be toward the lower limit (11.2\%), and there is an increase in the carbohydrate content after purification $(17.6 \%)$ which is higher than that of fucoidan $(12.8 \%)$. In the present study, the crude sample ESPS contain only less fucose but after purification, the percentage was found to be increased which is comparable to that of fucoidan. The sulfate content of the brown algae was reported to vary from 5\% to 17\% (Magalhaes et al., 2011; Vijayabaskar and Vaseela, 2012; Melo et al., 2013) and our results were also within this range. The total SPS content was also high in ESPS-CP than fucoidan. All the results of chemical composition revealed that the purified fraction is more effective than crude one on comparison with fucoidan. Moreover, the composition of biomolecules varies with species, maturity, growth environments, geographical locations, climate and harvesting seasons (Matanjun et al., 2009). In short, the column purification has removed much of the contaminants, which is evident from relative higher carbohydrate content in ESPS-CP. Still, ESPS-CP could not be claimed as the purest form and more purification strategies are needed to achieve the maximum purity. In the present study, we analyzed the bioactivity of ESPS-CP.

The phytochemical analysis of isolated crude polysaccharide revealed the presence of other active components also. Ulva lactuca, a green algae bears ample amounts of flavonoids, terpenoids, glycosides and alkaloids (Abd Elmegeed et al., 2014). A study by Govindappa et al. relates the phytochemical composition and the antioxidant property and revealed that the total phenol and flavanoid content contribute much to the free radical scavenging ability (Govindappa et al., 2013). Even though the phytochemicals are pharmacologically active, we removed much of them from our sample during the purification step and the purified sample showed only the presence of glycosides and reducing sugar.

DPPH radical (2,2-diphenyl-1-picrylhydrazyl radical) is a stable free radical, which is widely used to determine the radical scavenging activity of natural compounds. The method is based on the decrease of absorbance at $517 \mathrm{~nm}$ due reduction of purple colored DPPH radical to non-radical form (Do QD et al., 2014). In the present study, both our samples (ESPS and ESPS-CP) showed a considerable decrease in the absorbance at $517 \mathrm{~nm}$ with graded increase in the concentration. The proton donor groups like $-\mathrm{COOH}$ and $-\mathrm{SO}_{3} \mathrm{H}$ present in our SPS can contribute to the DPPH reducing the capacity of both samples. However, the samples are found to be effective between 2 and $2.5 \mathrm{mg} / \mathrm{ml}$ and similar results were reported elsewhere for many other antioxidant compounds too. In the case of SPS, most of the studies reported to possess activity at higher concentration (Yang et al., 2011). The SPS fraction from the brown algae Sargassum horneri, the effective concentration was reported to be $2.5 \mathrm{mg} / \mathrm{ml}$ (Shao et al., 2014). On comparing with ascorbic acid, the scavenging ability of both the samples was found to be lower. However, most SPS were reported to possess IC50 values around this range (Hu et al., 2010).

Hydroxyl radicals are the most reactive form of free radicals responsible for DNA damage and lipid peroxidation which can pave way to cancer and related complications (Senthilkumar et al., 2013). Thus, the ability to quench the hydroxyl radical is significant for an antioxidant compound. The method used in the current study was based on the scavenging of hydroxyl radical generated through Fenton reaction (ferric-ascorbateEDTA- $\mathrm{H}_{2} \mathrm{O}_{2}$ system) by antioxidant compound. Both ESPS and ESPS-CP showed a dose-dependent decrease in the absorbance with high $\mathrm{IC}_{50}$ values. A sulfated fucan from the brown algae $D$. delicatula showed moderate hydroxyl radical scavenging activity. At $0.5 \mathrm{mg} / \mathrm{ml}$, around $15 \%$ inhibition was observed (Magalhaes et al., 2011). At the same time ESPS and ESPS-CP exhibited higher activity at $0.5 \mathrm{mg} / \mathrm{ml}$. The recent reports revealed that the hydroxyl radical scavenging is not the major mechanism for scavenging ROS by polysaccharides (Melo et al., 2013). But the ability of SPS to suppress hydroxyl radical generation and removal of the hydroxyl radical can be correlated to their hydroxyl radical scavenging potential (Wang et al., 2008).

Metabolic processes in the body produce the superoxide anions. They are relatively weak oxidants but can interact with other molecules to produce secondary ROS such as hydroxyl radical, hydrogen peroxide and singlet oxygen and can leads to the oxidative damage to lipids, proteins and DNA (Wang et al., 2008). The results showed a considerable increase in the inhibition of superoxide radical with respect to the increasing concentration of both the samples. Furthermore, at $1.5 \mathrm{mg} / \mathrm{ml}$ both sample showed a significant superoxide radical scavenging effect. A heterofucan from the brown algae $D$. delicatula possess a very low superoxide radical scavenging activity of 5.7\% at $0.5 \mathrm{mg} / \mathrm{ml}$ concentration (Magalhaes et al., 2011). The SPS from another brown algae S. horneri showed 65\% 
inhibition of superoxide radical at $2.5 \mathrm{mg} / \mathrm{ml}$ (Shao et al., 2014). When compared to these results, both ESPS and ESPS-CP study evoked a significant superoxide radical scavenging ability. It was also reported that the superoxide scavenging ability of vitamin $\mathrm{C}$ at a concentration of $2.0 \mathrm{mg} / \mathrm{ml}$ is only $68.19 \%$ (Wang et al., 2008), which is lower than that of both the samples in our study.

Nitric oxide is a diffusible free radical generated by macrophages and neurons that involves in various physiological processes such as smooth muscle relaxation and neuronal signaling (Shukla et al., 2012). The antioxidants can compete with oxygen for nitric oxide generated from sodium nitroprusside and can reduce the formation of nitrite ions, which can be estimated by Griess reaction (Corpuz et al., 2013). In the present study, a dose-dependent decrease in the absorbance was observed for both samples. The column fraction showed a comparable activity to that of standard ascorbic acid. Only a very few reports are available on the nitric oxide scavenging efficiency of SPS. DEAE CP SPS from the marine algae Caulerpa racemosa showed 50\% inhibition of nitric oxide production at a concentration of $250 \mu \mathrm{g} / \mathrm{ml}$ (Mahendran and Saravanan, 2013). This is comparable to the result obtained for purified sample (ESPS-CP) of the present study. Hydrogen peroxide is a weak oxidant produced during metabolic processes and can produce hydroxyl radicals in the cell, which will lead to cell damages. The addition of antioxidants to $\mathrm{H}_{2} \mathrm{O}_{2}$ solution causes fast decrease in the absorbance at $230 \mathrm{~nm}$ (Ramani et al., 2012). In the present study, the crude sample (ESPS) showed a noticeable capability to scavenge. The results obtained for both samples are much higher than the hydrogen peroxide scavenging potential reported for fucoidan and hetero fucans from the algae Fucus vesiculosus and Padina gymnospora (Rocha de Souza et al., 2007).

The TAA shows the ability of a sample to donate electrons. The method is based on the reduction of molybdenum VI to molybdenum $\mathrm{V}$ to form a green colored phosphate/molybdenum V complex (Senthilkumar et al., 2013). Highly active compounds show an increase in the absorbance. In the present study, there was a dosedependent increase in the absorbance for all samples at $695 \mathrm{~nm}$. However, when compared to standard gallic acid, both sample showed only moderate result. Furthermore, a fucan from brown algae Dictyopteris justii, showed much higher antioxidant activity ( $1 \mathrm{mg} / \mathrm{ml}$ sample contains $82.9 \mu \mathrm{g} / \mathrm{ml}$ equivalence of ascorbic acid) when compared to our samples (Melo et al., 2013). Thus, we concluded that the TAA contributes less to the antioxidant potential of the extracts. Reducing the power of a compound is the significant indicator of its antioxidant activity (Liu et al., 2013). It is related to their electron transfer ability and they can act as primary and secondary antioxidants (Chaudhuri et al., 2014). An increase in the absorbance at $700 \mathrm{~nm}$ indicates high reducing ability. But the obtained result was found to be reduced when compared to the reducing capacity of SPS from other algal sources (Magalhaes et al., 2011).

The antioxidant activity of purified sample (ESPS-CP) was found to be less than that of crude one (ESPS). This can be explained by several reasons. The presence of polyphenols such as flavonoids in the crude sample contributes to its high antioxidant capacity when compared to the purified sample which is devoid of compounds other than SPS (Mak et al., 2013). The low sulfate content of the purified sample may also contributes to its low scavenging effect (Yang et al., 2011). In most of the antioxidant properties analyzed in our study, our SPS showed less activity when compared to ascorbic acid or gallic acid.

The biochemical similarity between plants and animals can be exploited to use plants as an alternative system for animal experiments for the development of new drugs (Nayak and Lakshmi, 2014). The chromosomal mutations in higher plant system can be directly correlated to the mammalian system (James et al., 2014; Nielsen and Rank, 1994). Growth inhibition assays in plants provide another better way of detecting the antimitotic potential of various drugs (Alamgir et al., 2014). Germination of green gram seeds and $A$. cepa test are the two common methods used to test antimitotic activity (Nayak and Lakshmi, 2014; Sadananda, 2013). The relative germination ratio of the seed will decrease with increase in the extract concentration (Mohamed and El-Ashry, 2012). It is also proven that that higher doses of extracts were much more effective in inhibiting seed germination (Alamgir et al., 2014). A dose-dependent decrease in the water imbibition and seed sprouting was observed in the current study. The inhibition of germination can be associated with reduction in water imbibition (Kumar and Singhal, 2009). This can further affect the osmotic potential to reduce the turgor pressure within the seed and hence prevent the radicle protrusion (Kumar and Singhal, 2009). The results show the non-selective cytotoxic effect of both the extracts. Potent anticancer drugs such as Lapachol and Quercetin were also showed a similar trend on seed germination (Sadananda, 2013).

Most of the chemotherapeutic drugs act by interrupting cell division (mitosis) in fast-dividing cells. The inhibition of mitosis in onion root tip is considered as a sensitive and 
easy method for the determination of cytotoxicity of drugs (Thenmozhi et al., 2011) and Allium test shows an excellent relationship with mammalian test systems. A standard anticancer drug such as methotrexate also showed a decrease in the mitotic index of onion root tip. A study about the inhibition of mitosis in onion root tip proved that there is a disturbance in the mitotic spindle formation and also inhibition of cell plate formation which may be due to the arrest of cell division at G2 phase or S phase (Yuet Ping et al., 2012). The inhibition of mitosis by both the extracts is beneficial for their possible applications for lifethreatening diseases such as cancer. Thus, we suggest that the cytotoxic action of both ESPS and ESPS-CP can involve disturbance of mitotic processes in the fast-dividing cancer cells which will be beneficial for cancer management (Mohamed and El-Ashry, 2012). Our samples, being capable of arresting the mitotic progression of plant cells; it may have the potential to find opportunities in arresting the cancer cell proliferation. More studies are required on the cellular and the molecular levels of animals (both in vitro and in vivo) to correlate these aspects with the cancer biology.

\section{CONCLUSION}

The present study signifies the SPS isolated from the brown algae $P$. tetrastromatica as a bioactive compound with antioxidant and antimitotic activity. Both the unpurified and ethanolic column purified fraction of the SPS can be used as an antioxidant and antimitotic compound. The isolated SPS fractions can be a good candidate for antioxidant therapies especially as the supplements in cancer therapeutics.

\section{ACKNOWLEDGMENTS}

We gratefully acknowledge UGC for providing the financial assistance in the form of Basic Scientific ResearchResearch Fellowship in Science for Meritorious Students (BSR-RFSMS).

\section{REFERENCES}

Abd Elmegeed DF, Ghareeb DA, Elsayed M, El-Saadani M. Phytochemical constituents and bioscreening activities of green algae (Ulva Lactuca). Int J Agric Policy Res 2014;2:373-8.

Alam S, Satpathy P,Thosar A. Plants and its parts as a source of anticancer compounds: A review. Int Res J Pharm 2014;5:244-9.

Alamgir AN, Rahman M, Rahman A. Phytochemical characteristics, antimitotic, cytotoxic and antiinflamatory activities of Coccinia grandis (L.) J. Voigt. J Pharmacogn
Phytochem 2014;3:222-5.

Ale MT, Maruyama H, Tamauchi H, Mikkelsen JD, Meyer AS. Fucose-containing sulfated polysaccharides from brown seaweeds inhibit proliferation of melanoma cells and induce apoptosis by activation of caspase- 3 in vitro. Mar Drugs 2011;9:2605-21.

Ali Hassan SH, Abu Bakar MF. Antioxidative and anticholinesterase activity of Cyphomandra betacea fruit. ScientificWorldJournal 2013;2013:278071.

AthukoralaY, JungWK, VasanthanT, JeonYJ. An anticoagulative polysaccharide from an enzymatic hydrolysate of Ecklonia cava. Carbohydr Polym 2006;66:184-91.

Badrinathan S, Shiju TM, Sharon Christa AS, Arya R, Pragasam V. Purification and structural characterization of sulfated polysaccharide from Sargassum myriocystum and its efficacy in scavenging free radicals. Indian J Pharm Sci 2012;74:549-55.

Bennett LL, Rojas S, Seefeldt T. Role of antioxidants in the prevention of cancer. J Exp Clin Med 2012;4:215-22.

Blackmore PF, Williams JF. Estimation of pentose 5-phosphate in the presence of heptulose and hexose phosphates by the orcinol method. Int J Biochem 1974;5:343-8.

Chaudhuri D, Ghate NB, Deb S, Panja S, Sarkar R, Rout J, et al. Assessment of the phytochemical constituents and antioxidant activity of a bloom forming microalgae Euglena tuba. Biol Res 2014;47:24.

Corpuz MJ, Osi MO, Santiago LA. Free radical scavenging activity of Sargassum siliquosum J. G. Agardh. Int Food Res J 2013;20:291-7.

Costa LS, Fidelis GP, Telles CB, Dantas-Santos N, Camara RB, Cordeiro SL, et al. Antioxidant and antiproliferative activities of heterofucans from the seaweed Sargassum filipendula. Mar Drugs 2011;9:952-66.

da Rocha AB, Lopes RM, Schwartsmann G. Natural products in anticancer therapy. Curr Opin Pharmacol 2001;1:364-9.

Dayem AA, Choi HY, Kim JH, Cho SG. Role of oxidative stress in stem, cancer, and cancer stem cells. Cancers (Basel) 2010;2:859-84.

Do QD, Angkawijaya AE, Tran-Nguyen PL, Huynh LH, Soetaredjo FE, Ismadji S, et al. Effect of extraction solvent on total phenol content, total flavonoid content, and antioxidant activity of Limnophila aromatica. J Food Drug Anal 2014;22:296-302.

Finosh GT, Jayabalan M, Vandana S, Raghu KG. Hybrid alginate-polyester bimodal network hydrogel for tissue engineering - Influence of structured water on long-term cellular growth. Colloids Surf B Biointerfaces 2015. pii: S0927-776500154-X.

Finosh GT, Jayabalan M. Hybrid amphiphilic bimodal hydrogels having mechanical and biological recognition characteristics for cardiac tissue engineering. RSC Adv 2015;5:38183-201. 
Govindappa M, Channabasava R, Kumar KR, Pushpalatha KC. Antioxidant activity and phytochemical screening of crude endophytes extracts of \&amp;lt;i\&amp;gt; Tabebuia argentea\&amp;lt; /i\&amp;gt; Bur. \&amp;amp; K. Sch. Am J Plant Sci 2013;4:1641-52.

Hu T, Liu D, Chen Y, Wu J, Wang S. Antioxidant activity of sulfated polysaccharide fractions extracted from Undaria pinnitafida in vitro. Int J Biol Macromol 2010;46:193-8.

James OO, Oluwaleye SE, Olufunmilayo AE, Adebiyi OA. Cytotoxic effects and genotoxic screening of pharmaceutical effluents using onion bulbs (Allium cepa L.). J Adv Biol Biotechonol 2014;2:51-8.

Kelman D, Posner EK, McDermid KJ, Tabandera NK, Wright PR, Wright AD. Antioxidant activity of Hawaiian marine algae. Mar Drugs 2012;10:403-16.

Kumar V, Nagar S, Tripathi YC. Do assorted approaches aid in estimation of uronic acids? Case studies on Tinospora sinensis polysaccharides. Int J Biol Macromol 2014;70:360-3.

Kumar VL, Singhal A. Germinating seeds of the mung bean, Vigna radiata (Fabaceae), as a model for the preliminary evaluation of cytotoxic effects of drugs. Biocell 2009;33:19-24.

Li B, Lu F, Wei X, Zhao R. Fucoidan: Structure and bioactivity. Molecules 2008;13:1671-95.

Liao D, Wang X, Lin PH, Yao Q, Chen CJ. Covalent linkage of heparin provides a stable anti-coagulation surface of decellularized porcine arteries. J Cell Mol Med 2009;13:2736-43.

Liu J, Jia L, Kan J, Jin CH. In vitro and in vivo antioxidant activity of ethanolic extract of white button mushroom (Agaricus bisporus). Food Chem Toxicol 2013;51:310-6.

Magalhaes KD, Costa LS, Fidelis GP, Oliveira RM, Nobre LT, Dantas-Santos N, et al. Anticoagulant, antioxidant and antitumor activities of heterofucans from the seaweed Dictyopteris delicatula. Int J Mol Sci 2011;12:3352-65.

Mahendran S, Saravanan S. Purification and in vitro antioxidant activity of polysaccharide isolated from green seaweed Caulerpa racemosa. Int J Pharm Bio Sci 2013;4:1214-27.

Mak W, Hamid N, Liu T, Lu J, White WL. Fucoidan from New Zealand Undaria pinnatifida: Monthly variations and determination of antioxidant activities. Carbohydr Polym 2013;95:606-14.

Manochai B, Paisooksantivatana Y, Choi H, Hong JH. Variation in DPPH scavenging activity and major volatile oil components of cassumunar ginger, Zingiber montanum (Koenig), in response to water deficit and light intensity. Sci Hortic 2010;126:462-6.

Matanjun P, Mohamed S, Mustapha NM, Muhammad K. Nutrient content of tropical edible seaweeds, Eucheuma cottonii, Caulerpa lentillifera and Sargassum polycystum. J Appl Phycol 2009;21:75-80.
Melo KR, Camara RB, Queiroz MF, Vidal AA, Lima CR, MeloSilveira RF, et al. Evaluation of sulfated polysaccharides from the brown seaweed Dictyopteris justii as antioxidant agents and as inhibitors of the formation of calcium oxalate crystals. Molecules 2013;18:14543-63.

Mohamed FI, El-Ashry ZM. Cytogenetic effect of allelochemicals Brassica nigra L. Extracts on Pisum sativum L. World Appl Sci J 2012;20:344-53.

Mohan DS, Saraswathy M, Kurup MK. Attenuation of hyperglycemia and hyperlipidemia in high calorie fed/streptozotocin-treated rats by hydromethanolic extract of Padina tetrastromatica. Bangladesh J Pharmacol 2014;9:389-97.

Nayak NI, Lakshmi P. Seed germination: An alternative to animal model to teach bioassay principles. J Pharmacol Pharmacother 2014;5:56-8.

Ngo DH, Kim SK. Sulfated polysaccharides as bioactive agents from marine algae. Int J Biol Macromol 2013;62:70-5.

Nielsen MH, Rank J. Screening of toxicity and genotoxicity in wastewater by the use of the Allium test. Hereditas 1994;121:249-54.

Ogasawara MA, Zhang H. Redox regulation and its emerging roles in stem cells and stem-like cancer cells. Antioxid Redox Signal 2009;11:1107-22.

Patwardhan B, Vaidya AD. Natural products drug discovery: Accelerating the clinical candidate development using reverse pharmacology approaches. Indian J Exp Biol 2010;48:220-7.

Qi H, Zhang Q, Zhao T, Chen R, Zhang H, Niu X, et al. Antioxidant activity of different sulfate content derivatives of polysaccharide extracted from Ulva pertusa (Chlorophyta) in vitro. Int J Biol Macromol 2005;37:195-9.

Ramani R, Sudini S, Boddupalli BM, Anisetti RN. Antioxidant, free radical scavenging and invitro cytotoxic studies of ethanolic extract of Leucas indica var lavandulifolia and Leucas indica var nagalapuramiana. Asian Pac JTrop Biomed 2012;2:S1637-42.

Rocha de Souza MC, Marques CT, Guerra Dore CM, Ferreira da Silva FR, Oliveira Rocha HA, Leite EL. Antioxidant activities of sulfated polysaccharides from brown and red seaweeds. J Appl Phycol 2007;19:153-160.

Saboo SS, Khadabadi S, Tapadiya GG. In vitro evaluation of antimitotic, antiproliferative, DNA fragmentation and anticancer activity of chloroform and ethanol extracts of revia hypocrateriformis. Asian Pac J Trop Dis 2012;2 Suppl 1:S503-8.

Saboural P, Chaubet F, Rouzet F, Al-Shoukr F, Azzouna RB, Bouchemal N, et al. Purification of a low molecular weight fucoidan for SPECT molecular imaging of myocardial infarction. Mar Drugs 2014;12:4851-67.

Sadananda TS. Evaluation of cytotoxic activities of endophytic 
fungal lectin from Viscum album using in vitro model systems. Int J Compr Pharm 2013;8:1-9.

Sawke NG, Sawke GK. Serum fucose level in malignant diseases. Indian J Cancer 2010;47:452-7.

Schwartsmann G, Brondani da Rocha A, Berlinck RG, Jimeno J. Marine organisms as a source of new anticancer agents. Lancet Oncol 2001;2:221-5.

Senthilkumar K, Manivasagan P, Venkatesan J, Kim SK. Brown seaweed fucoidan: Biological activity and apoptosis, growth signaling mechanism in cancer. Int J Biol Macromol 2013;60:366-74.

Senthilkumar R, ParimelazhaganT, Chaurasia OP, Srivastava RB. Free radical scavenging property and antiproliferative activity of Rhodiola imbricata Edgew extracts in HT-29 human colon cancer cells. Asian Pac J Trop Med 2013;6:11-9.

Sethi P. Biochemical composition of marine brown algae, Padina tetrastromatica hauck. Int J Curr Pharm Res 2012;4:117-8.

Shao P, Chen X, Sun P. Chemical characterization, antioxidant and antitumor activity of sulfated polysaccharide from Sargassum horneri. Carbohydr Polym 2014;105:260-9.

Shukla S, Mehta A, Mehta P, Bajpai VK. Antioxidant ability and total phenolic content of aqueous leaf extract of Stevia rebaudiana Bert. Exp Toxicol Pathol 2012;64:807-11.

Singh D, Singh P, Gupta A, Solanki S, Sharma E, Nema R. Qualitative estimation of bioactive compound present in Centella Asiatica: An important medicinal plant. Int J Life Sci Med Res 2012;2:5-7.

Suresh V, Senthilkumar N, Thangam R, Rajkumar M, Anbazhagan C, Rengasamy R, et al. Separation, purification and preliminary characterization of sulfated polysaccharides from Sargassum plagiophyllum and its in vitro anticancer and antioxidant activity. Process Biochem 2013;48:364-73.

Thenmozhi A, Nagalakshmi A, Mahadeva Rao US. Study of cytotoxic and antimitotic activities of Solanum nigrum by using Allium cepa root tip assay and cancer chemo preventive activity using MCF-7-human mammary gland breast adenocarcinoma cell lines. Int J Sci Technol 2011;1:26-47.

Thinh PD, Menshova RV, Ermakova SP, Anastyuk SD, Ly BM, Zvyagintseva TN. Structural characteristics and anticancer activity of fucoidan from the brown alga Sargassum mcclurei. Mar Drugs 2013;11:1456-76.

Thomas NV, Kim SK. Beneficial effects of marine algal compounds in cosmeceuticals. Mar Drugs 2013;11:146-64.

Vijayabaskar P, Vaseela N. In vitro antioxidant properties of sulfated polysaccharide from brown marine algae Sargassum tenerrimum. Asian Pac J Trop Dis 2012;2:S890-6.

Wadood A. Phytochemical analysis of medicinal plants occurring in local area of mardan. Biochem Anal Biochem 2013;2:144.

Wang J, Zhang Q, Zhang Z, Li Z. Antioxidant activity of sulfated polysaccharide fractions extracted from Laminaria japonica. Int J Biol Macromol 2008;42:127-32.

YangY, Liu D, Wu J, ChenY, Wang S. In vitro antioxidant activities of sulfated polysaccharide fractions extracted from Corallina officinalis. Int J Biol Macromol 2011;49:1031-7.

Yuet Ping K, Darah I, Yusuf UK, Yeng C, Sasidharan S. Genotoxicity of Euphorbia hirta: An Allium cepa assay. Molecules 2012;17:7782-91.

Zhao Y, Du SK, Wang H, Cai M. In vitro antioxidant activity of extracts from common legumes. Food Chem 2014;152:462-6. 